\title{
Agôn
}

Revue des arts de la scène

Critiques | Saison 2014-2015

\section{Orpheus In The Land of The Living, du collectif andcompany\&Co}

Orphée face à l'Europe forteresse

\section{Charlotte Bomy}

\section{CpenEdition}

Journals

Édition électronique

URL : http://journals.openedition.org/agon/3167

DOI : $10.4000 /$ agon.3167

ISSN : 1961-8581

Éditeur

Association Agôn

Référence électronique

Charlotte Bomy, "Orpheus In The Land Of The Living, du collectif andcompany\&Co », Agôn [En ligne],

Critiques, mis en ligne le 24 mars 2015, consulté le 23 septembre 2020. URL : http://

journals.openedition.org/agon/3167; DOI : https://doi.org/10.4000/agon.3167

Ce document a été généré automatiquement le 23 septembre 2020.

Association Agôn et les auteurs des articles 


\title{
Orpheus In The Land of The Living, du collectif andcompany\&Co
}

\author{
Orphée face à l'Europe forteresse
}

\section{Charlotte Bomy}

\section{RÉFÉRENCE}

Orpheus In The Land Of The Living, du collectif andcompany\&Co

www.andco.de/

Création le 10 octobre 2014 au HAU à Berlin; en tournée les 3 et 4 février 2015 à

l'Hippodrome de Douai.

Dans l'obscurité, on distingue d'abord une île artificielle composée de rochers gris ; puis, en fond de scène, un grillage épais et imposant, tel un mur infranchissable - ou plutôt une frontière. Une station électronique est installée à jardin. Un DJ en imperméable noir y distille une musique d'ambiance sourde, à laquelle répondent trois musiciens avec des instruments électro-acoustiques (violoncelle, flûte, clavier), postés de l'autre côté de la scène. Lorsque ces derniers reprennent des airs de l'orfeo de Monteverdi, les six comédiens s'avancent furtivement sur scène, dissimulés sous des cirés jaunes ou des ponchos comme pour se protéger des intempéries, ou bien pour rester anonymes. Ce sont les passeurs, les « hors-la-loi » : les porte-voix de tous ceux qui passent et font passer les migrants en quête d'Europe par le delta de l'Évros.

2 Frontière politique naturelle entre la Grèce et la Turquie, et entre la Turquie et la Bulgarie, le fleuve Évros est aussi le point de départ géographique du nouveau spectacle de la andcompany\&Co., le collectif berlinois co-dirigé par la metteuse en scène Nicola Nord, l'auteur et performer Alexander Karschnia et le musicien Sascha Sulimma. Au même titre que Lampedusa, ou que Ceuta et Melilla, l'Évros est devenu ces dernières années synonyme de traversée mortelle: un no man's land bordé de grillages où les garde-frontières patrouillent jour et nuit pour traquer les immigrants «illégaux » ou plutôt il-légalisés ${ }^{1}$. 
Comme à son habitude, le trio fondateur de la andcompany est accompagné par d'autres performers (le fameux «\&Co.» qui varie d'un projet à l'autre), notamment le contreténor Georg Bochow et le baryton Bora Balci. Le spectacle fonctionne selon une alternance de moments musicaux - d'influence baroque ou pop, tous réécrits à la manière de songs brechtiens - et de monologues (parfois à plusieurs voix) où chaque comédien s'adresse au public et semble parler en son propre nom pour interroger la figure du passeur. Le comédien Knut Berger souligne d'abord à quel point le mot allemand pour «passeur » («Schlepper ») a la connotation négative de trafiquant ou contrebandier. Mais on apprend aussi que les passeurs sont des «facilitateurs" de passages, des guides, des médiateurs, des éclaireurs : à une autre époque, ils étaient les sauveurs de ceux qui fuyaient l'Europe fasciste (comme Brecht) - ou, plus récemment, les protecteurs de ceux qui voulaient passer le Rideau de fer, de l'Allemagne de l'Est à l'Allemagne de l'Ouest. Ludique et didactique à la fois, chaque prise de parole apporte un contrepoint nouveau et parfois contradictoire, permettant d'envisager le statut ambigu du passeur, tantôt sauveur, tantôt profiteur.

Orpheus In The Land of The Living est un spectacle qui pense la question des frontières et plus particulièrement celles, paradoxales, de l'Europe : depuis l'invention de l'alphabet grec jusqu'à la constitution d'un espace européen - dont la logique est définitivement plus économique que géographique -, en passant par la «liberté de circulation" accordée exclusivement aux citoyens de l'UE. La frontière unit, protège par des privilèges, en même temps qu'elle exclut, exploite ceux qui sont de l'autre côté du mur. Perchés sur des rochers mobiles et casqués de «têtes » d'oiseaux rares, les performers nous racontent l'autre réalité du delta de l'Évros qui est une étape, un passage pour de nombreux oiseaux migrateurs; aigles, hérons, pélicans, cormorans, cigognes... Un paradis ornithologique, doublé d'un cimetière humain. Soudain, des cris d'oiseaux samplés se mêlent au trio instrumental et l'image se renverse: la lyre d'un des chanteurs, qui a la forme du symbole de l'euro, se transforme en arme menaçante de Frontex pour assommer et capturer ces oiseaux migrants.

5 Impossible d'évoquer l'errance des migrants et l'injustice de l'Europe forteresse sans parler de Frontex : l'agence européenne de surveillance des frontières extérieures qui met au point des dispositifs de surveillance de plus en plus répressifs et dont le budget a été multiplié par quinze ces dix dernières années ${ }^{2}$. L'actrice grecque Irida Baglanea nous rappelle que les opérations de patrouille (maritimes ou terrestres) de Frontex portent toujours des noms issus de la mythologie (Opération Poséidon, Opération Héra...) $)^{3}$. D'où sa proposition concrète: pourquoi ne pas parler d'une "Opération Orpheus " pour décrire des push-backs (ou refoulements) violents de migrants réalisés par Frontex aux frontières extérieures? Après tout, Orphée a bel et bien renvoyé sa bien-aimée Eurydice aux Enfers...

6 À l'image de la pieuvre géante rouge qui apparaît à la fin du spectacle pour figurer l'espace de contrôle des frontières européennes, cet Orpheus est lui-même un objet tentaculaire qui touche à des thèmes brûlants à partir de différentes perspectives ; c'est en même temps le fruit d'une écriture collective qui mélange les genres avec une intelligence et une lucidité critique rares. 


\section{NOTES}

1. À propos de ce terme, je renvoie à la note de recherche de Harald Bauder (Ryerson Université, Toronto) : «Pourquoi devrions-nous utiliser le terme immigrant il-légalisé » (2013) dont la traduction française est disponible sur le site de la Cimade.

2. Voir, à ce sujet, l'ouvrage éclairant de Claire Rodier, Xénophobie Business. À quoi servent les contrôles migratoires? La Découverte, Paris, 2012.

3. L'Agence Frontex était déjà le sujet d'un spectacle récent du metteur en scène Hans-Werner Kroesinger qui pratique un théâtre documentaire régulièrement présenté au HAU à Berlin (FRONTEX Security en 2013). 